\title{
Corrosion Mechanism Suggested Based on Electrochemical Analysis and SVET for Uncoated Tinplate and Post Coated With a Hybrid Film
}

\author{
Sandra Raquel Kunst ${ }^{a *}$, Lilian Vanessa Rossa Beltrami ${ }^{b}$, Rosiana Boniattic, Marcela C. Quevedo ${ }^{d}$, \\ Alexandre C. Bastos ${ }^{d}$, Cláudia Trindade Oliveira ${ }^{a}$, Mário Ferreirad, Tiago L. Menezese , Célia F. Malfatti ${ }^{e}$ \\ ${ }^{a}$ Instituto de Ciências Exatas e Tecnologias - ICET, Universidade Feevale, Novo Hamburgo, RS, Brazil \\ ${ }^{b}$ Programa de Pós-Graduação em Engenharia de Processos e Tecnologias - PGEPROTEC, \\ Universidade de Caxias do Sul - UCS, Caxias do Sul, RS, Brazil \\ ${ }^{c}$ Laboratório de Corrosão - LACOR, Universidade Federal do Rio Grande do Sul - UFRGS, Porto \\ Alegre, RS, Brazil \\ ${ }^{d}$ Departamento de Engenharia de Materiais e Cerâmica - DEMAC, Universidade de Aveiro, Campus \\ Santiago, Aveiro, Portugal \\ ${ }^{e}$ Laboratório de Pesquisa em Corrosão - LAPEC, Universidade Federal do Rio Grande do Sul - \\ UFRGS, Porto Alegre, RS, Brazil
}

Received: August 29, 2016; Revised: July 10, 2017; Accepted: September 04, 2017

\begin{abstract}
The tinplate, used in the packaging sector and formed from a metal substrate, comprises a steel base which has undergone a surface treatment to produce a thin layer of $\mathrm{FeSn}_{2}$, a tin layer and an oxide tin layer. Currently, packaging using surface treatment is based on the use of chromates because these metals provide an excellent corrosion resistance. Nontoxic alternatives to pre-treatments have been developed in recent years to replace the chromate process. The aim of this work is to analyze the performance of a new hybrid organic-inorganic film obtained from sol-gel consisting of the alkoxide precursors 3-(Trimethoxysilylpropyl)methacrylate (TMSM) and tetraethoxysilane (TEOS) with the addition of cerium nitrate with the scanning vibrating electrode technique (SVET), and electrochemical and morphological characterizations. Moreover, the evolution of the corrosion of the substrate was evaluated to propose a mechanism of corrosion. The results showed a galvanic coupling between the $\mathrm{Sn} / \mathrm{SnO}_{2}$ coat (cathode) and the defects exposed at the ferrous base (anode). The organic-inorganic hybrid film containing a cathodic corrosion inhibitor was able to retard the corrosion of the tinplate.
\end{abstract}

Keywords: tinplate, corrosion, SVET, hybrid films

\section{Introduction}

Tinplate is a thin low-carbon mild steel sheet, cold reduced, coated on both sides with pure electrolytic tin, linking the strength and formability of the steel with the corrosion resistance and weldability of the $\operatorname{tin}^{1,2}$. Tinplate is largely used in food packaging, being ideally suited for this purpose since it is non-toxic, light strong, and resistant to corrosion ${ }^{3}$. Tinplate consists of a steel sheet with a typical thickness of $0.1-0.5$ $\mathrm{mm}$ coated with a thin layer of electrolytically deposited tin.

This combination renders the material a non-corrosive characteristic. Further protection was achieved by including an organic top layer. Figure 1 shows the obtained layers from the iron base to the top-coat.

The resulting coating has the following stratified structure from bottom to top: a FeSn $\mathrm{S}_{2}$ alloy developed from flow-brightening which protects the steel against galvanic corrosion by oxidant species ${ }^{4}$.

The thickness of the metal sheet significantly influences the mechanical properties of the material. Along the

*e-mail: tessaro.sandra@gmail.com years, researchers have been working on modifying the thickness of these materials, aiming, among other things, to reduce costs. Steel represents up to $80 \%$ of the cost of packaging and any reduction in thickness of the plate is economics ${ }^{5,6}$.

Regarding the quality of tinplate, it is worth mentioning the presence of tin oxide on the surface and the passivation layer. Typically, the tinplate has a full or partial coverage of tin oxides $\left(\mathrm{SnO}_{\mathrm{x}}\right)$, which may contain stannous oxide ( $\mathrm{SnO}$ ) or stannic oxide, including its hydrated forms. The presence of excessive amounts of these oxides can change the appearance, the weldability of the metal sheet and the ability to receive organic coatings ${ }^{6,7}$.

A critical point is observed in the welded region, where the tinplate steel is more exposed due to the partial removal of the tin by the copper wire and its detachment from the surroundings due to the temperature and pressure applied in the welding process. This step removes much of the tin from the tinplate. Moreover, the welding structure, which has an uneven thickness, becomes difficult to be completely coated with organic coatings ${ }^{7,8}$. 


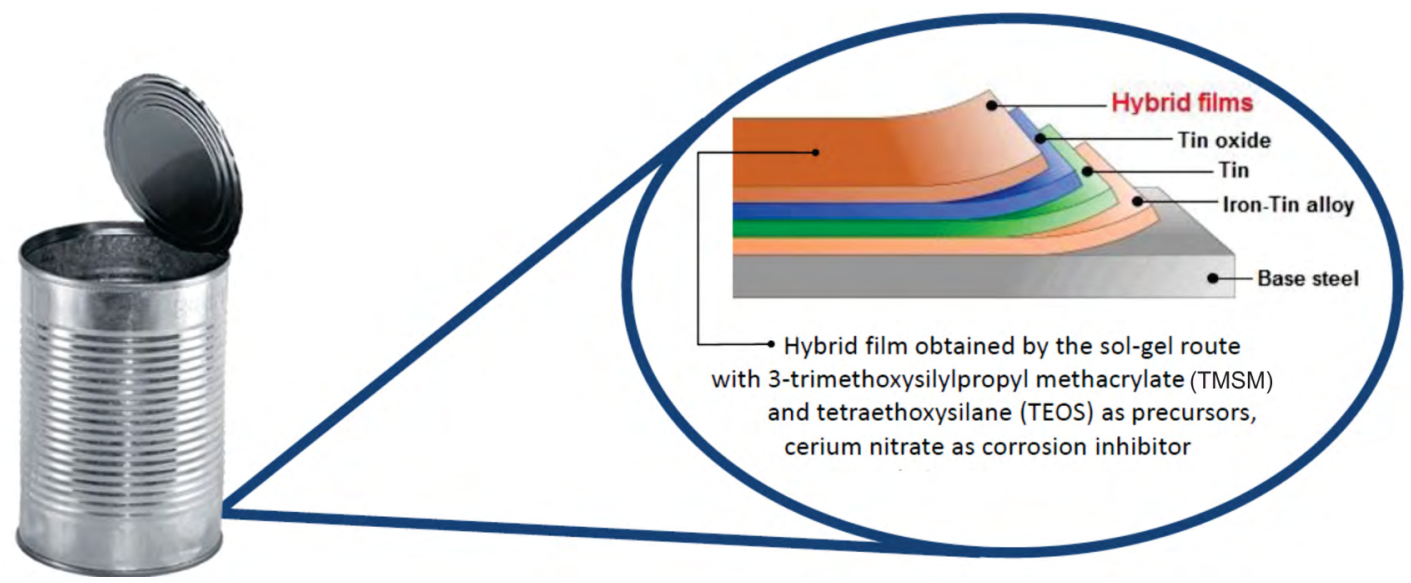

Figure 1. Illustrates system showing the layers obtained from the iron-base to the top coating.

The corrosion rate of a metal protected by an organic coating is related to several aspects, such as the transport of ionic species through the coating, the charge transfer processes in the metal-coating interface, delamination, and changes in the composition of the organic matrix. The performance of a coated metal depends on the polymeric material, porosity, interfacial adhesion, the environment, as well as the integrity of the coating thickness and composition. In a metal-coated polymer system, the formed corrosion products exert tension in the film coating, causing it to break, increasing the number of defects, with a consequent decrease in the pore resistance of the coating ${ }^{9,10}$.

Currently, packaging is submitted to a chromatebased surface treatment, for it offers excellent corrosion resistance ${ }^{11,12}$. Chromates, one of the most efficient types of pretreatments, have been extensively used for a long time. However, the same properties that contribute to a superior corrosion resistance of the thin layers also make them environmentally hazardous. Owing to increasing concerns regarding environmental protection and potential health hazards associated with chromates, their use is being heavily restricted ${ }^{13,14}$.

Nevertheless, non-toxic pre-treatments have been developed to substitute the chromatization process ${ }^{15,16}$. For this reason, the hybrid films have been proposed, since they are associated as part of a same matrix, with organic and inorganic components and combine the most important properties of each constituent ${ }^{17,18}$. Because they are compatible with overlying organic top-coats, eco-friendly sol-gel derived coatings can also present good adhesion to metallic surfaces via chemical bonding ${ }^{19}$.

Furthermore, due the numerous application parameters and curing of hybrid films, an enhanced adhesion might be expected, as metallosiloxane bonds are formed during the condensation reaction. Formation of siloxane chains through the condensation of silanol groups in excess could also yield a dense network layer acting as an effective barrier against aggressive species ${ }^{18-20}$.
The scanning vibrating electrode technique (SVET) has been applied to characterize a great variety of corrosion systems $^{21-24}$. The visualization of the corrosion progression is given in terms of the identification of anodic and cathodic regions with an estimation of the respective currents and their evolution ${ }^{25}$.

The objective of this work is to analyze the corrosion mechanism of tinplate with and without a hybrid organicinorganic film. The hybrid organic-inorganic film was obtained from sol consisting of the alkoxide precursors 3-(Trimethoxysilylpropyl) methacrylate (TMSM) and tetraethoxysilane (TEOS) with the addition of cerium nitrate. The corrosion was evaluated by electrochemical and morphological characterizations.

\section{Experimental Procedures}

\subsection{Surface preparation}

Tinplate sheets with dimensions of $20 \times 40 \mathrm{~mm}$ were obtained from an industrial sheet provided by CSN Company, rinsed with acetone and dried. Then, the plates were degreased by using the neutral detergent from Klintex Insumos, by immersion for $10 \mathrm{~min}$ at $70^{\circ} \mathrm{C}$, washed and dried. Table 1 shows the composition of the steel sheet before receiving the tin electrodeposition used in this work.

\subsection{Elaboration of hybrid films}

Hydrolysis reactions were conducted with the silane precursors (TEOS) tetraethoxysilane $\left(\mathrm{C}_{8} \mathrm{H}_{20} \mathrm{SiO}_{4}\right)$ and (TMSM) 3-(trimethoxysilyl)propylmethacrylate $\left(\mathrm{C}_{10} \mathrm{H}_{20} \mathrm{SiO}_{5}\right)$, which were obtained from Aldrich. Reactions were conducted in TEOS/TMSM/alcohol/water solutions in the molar ratio $1 / 0.125 / 10.327 / 7.875 \mathrm{M}$, respectively, with the addition of $0.01 \mathrm{M}$ cerium nitrate ${ }^{26}$. After 24 hours of hydrolysis, there were no significant differences in the $\mathrm{pH}$ values, which were in the range of $\mathrm{pH} 4.6$ to $\mathrm{pH} 4.75$. 
Table 1. Specification obtained by the provider of the steel sheet before receiving the tin electrodeposition.

\begin{tabular}{ccccccccc}
\hline Element (\%) & $\mathrm{C}_{\text {máx. }}$ & $\mathrm{Mn}_{\text {máx. }}$ & $\mathrm{P}_{\text {máx. }}$ & $\mathrm{S}_{\text {máx. }}$ & $\mathrm{Si}_{\text {máx. }}$ & $\mathrm{Al}$ & $\mathrm{N}_{\text {máx. }}$ \\
\hline & 0.06 & 0.2 & 0.02 & 0.02 & 0.02 & $0.02-0.06$ & 0.005 \\
\hline
\end{tabular}

Hydrolyzed hybrid solutions were applied by dip coating with an immersion time of 5 minutes and a removal rate of $10 \mathrm{~cm} \cdot \mathrm{min}^{-1}$. After the dip coating process the samples were cured at $60{ }^{\circ} \mathrm{C}$ for 20 minutes ${ }^{27,28}$. A description of the samples is presented on Table 2, and the protocol for the sol preparation as well as for the coatings is detailed on the flow chart (Figure 2).

\subsection{Experimental techniques}

The morphological characterization was carried out by scanning electron microscopy (SEM), performed in a JEOL 6060 device, with an acceleration voltage of $20 \mathrm{kV}$. The samples were observed in top view and in cross-section to determine the layer thickness.

Sample surface roughness was determined by the CETRPRO5003D profilometer. Three areas were analyzed in each sample to determine the average roughness ( $\mathrm{Ra})$. For this kind of analysis, some geometric parameters should be specified, as sample size. These values were determined by the expected roughness as recommended by ISO 4288 standard (ISO 4288:1996, 1996).

The corrosion performance of the coatings was evaluated by open circuit potential (Ecor) monitoring and electrochemical impedance spectroscopy (EIS) measurements in a $0.05 \mathrm{M} \mathrm{NaCl}$ solution. This concentration is sufficiently high to activate corrosion in a relatively short exposure time, but low enough to enable the effects of various acids to be determined, and allows the observation of corrosion inhibitor effects. A three-electrode cell was used to perform the analysis, with a platinum wire as the counter electrode and SCE as the reference electrode. The working electrode

Table 2. Description of the samples used.

\begin{tabular}{cc}
\hline Sample & Description \\
\hline TP-R & Tinplate without coating - reference \\
TP-HF & Tinplate coated with a hybrid film \\
\hline
\end{tabular}

area was $0.626 \mathrm{~cm}^{2}$. For the EIS measurements, the systems were previously monitored for up to 96 hours. The amplitude of the EIS perturbation signal was $10 \mathrm{mV}$, and the frequency ranged from $100 \mathrm{kHz}$ to $10 \mathrm{mHz}$ using a NOVA frequency response analyzer system and an AUTOLAB PGSTAT 30 potentiostat.

The SVET tests were carried out in the Materials and Ceramic Engineering Department at the University of Aveiro, Portugal, using equipment from Microprobes(r) Inc. (USA) and controlled by the ASET ScienceWares software (USA). The electrolyte used in this analysis was $0.05 \mathrm{M} \mathrm{NaCl}$ solution.

The vibrating electrode was made of platinum-iridium alloy covered with polymer, with the tip uncovered, with a diameter of $10-20 \mathrm{~mm}$. The signals considered in this study were only the ones from the normal field. The frequency was $162 \mathrm{~Hz}$ and the vibration amplitude was twice the diameter of the tip. The measured potential differences are converted into ionic currents after a calibration routine performed with a current source point (microelectrode with a tip $\sim 3 \mathrm{~mm}$ ) conducting a current of $60 \mathrm{nA}$ to $150 \mathrm{~mm}$ from the vibration sensor. The calibration is valid for a new solution, since the system was updated with its resistivity. Maps were obtained to a $100 \mathrm{~mm}$ plane above the sample surface.

\section{Results and Discussion}

\subsection{Morphological characterization}

Figure 3 shows a cross-section analyzed by SEM/ EDS of the tinplate sheets that were received as well as the thickness of the tin layer.

Figure 4 shows SEM micrographs for the hybrid film before the electrochemical tests as well as the thickness of the layer of the hybrid films as determined by the SEM analysis of the cross section. The top micrograph shows that the forming accumulations may have occurred during the condensation
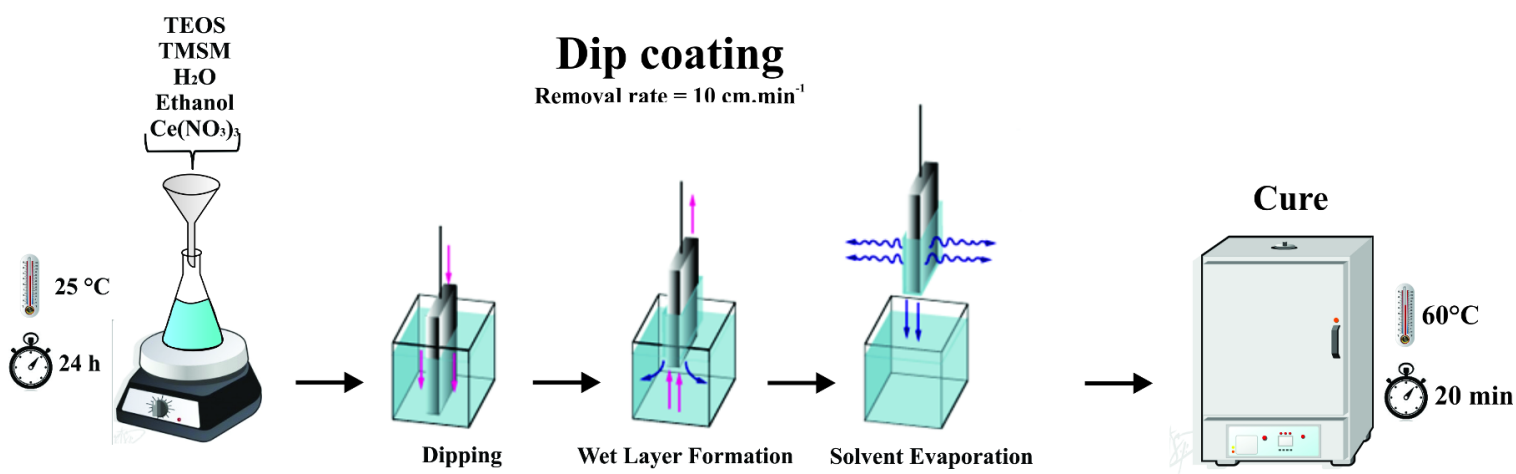

Figure 2. Flowchart of the experimental process. 


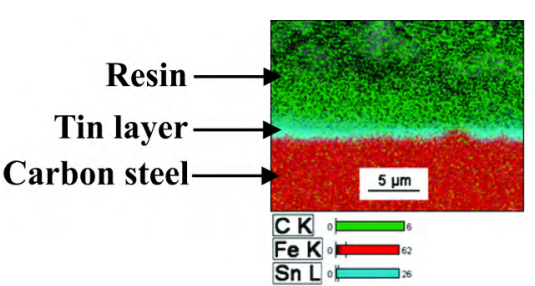

Average value of the tin layer: $1.04 \mu \mathrm{m} \pm 0.13$

Figure 3. Cross section analyzed by SEM / EDS tinplate as received.
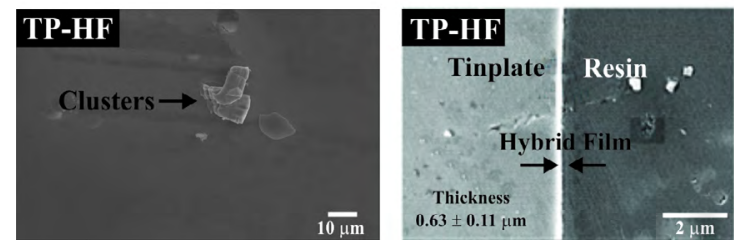

Figure 4. Micrographs obtained by SEM (top and cross section) for the hybrid film obtained.

reaction of the film due to the precipitation of agglomerates with a higher concentration of Si due to the addition of TEOS which provides more silicon groups to this film. Besides, a higher densification of this film was observed ${ }^{29}$, which is due to the covalent bonds of the organic and inorganic precursors. This demonstrates the perfect interaction of TMSM and TEOS precursors present in the hybrid film.

The obtained layer is $0.63 \mathrm{~mm}(0.11 \mathrm{~mm})$ thick. The layer formation can be associated with the fact that the presence of TEOS in the film increases the number of silanol groups and, consequently, the inorganic phase amount (siloxane) increases. This proportion of TEOS was sufficient to produce the synergistic effect of the presence of TMSM and TEOS precursors in the hybrid film ${ }^{30}$. Other studies by Si NMR for these unsupported films showed an increase the condensation degree as a function of TEOS/TMSM ratio increase, obtaining values from $78 \%$ to $85 \%$. This increase is manly due to the heterocondensation that occurs between the TEOS and the TMSM which results in siloxane crosslinking reactions and, consequently, in the formation of a dense hybrid network contributing to the thickness and adhesion of the films ${ }^{31}$.

Figure 5 shows three-dimensional images obtained by profilometry and the determined roughness values are shown in Table 3. The average roughness (Ra) of TP-R and TP-HF samples are very similar. However, the peak to peak roughness of TP-HF sample was higher when compared to sample TP-R. This can be occurred due to irregularities and clusters on the surface of the TP-HF sample.

\subsection{Electrochemical characterization}

\subsubsection{Open circuit potential monitoring}

The open circuit potential (OCP) was conducted in an $0.05 \mathrm{M} \mathrm{NaCl}$ solution, to check the potential variation with time. The results of the OCP monitoring are shown in Figure 6. It was found that the TP-HF hybrid films had their potential
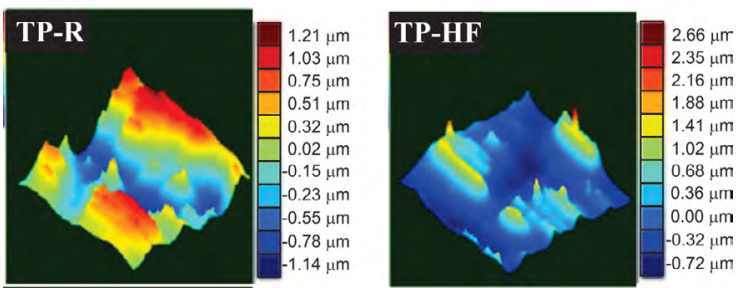

Figure 5. 3D images profilometry obtained by the samples.

Table 3. Samples roughness values, determined by profilometry analysis.

\begin{tabular}{cccc}
\hline \multirow{2}{*}{ Sample } & \multicolumn{3}{c}{ Surface roughness } \\
\cline { 2 - 4 } & $\mathrm{Ra}(\mu \mathrm{m})$ & $\mathrm{Rms}(\mu \mathrm{m})$ & Peak to peak $(\mu \mathrm{m})$ \\
\hline \multirow{2}{*}{ TP-R } & $0.43 \pm$ & $0.51 \pm 0.31$ & $2.40 \pm 0.83$ \\
& 0.27 & & $3.53 \pm 0.37$ \\
TP-HF & $0.40 \pm$ & $0.50 \pm 0.33$ & \\
\hline
\end{tabular}

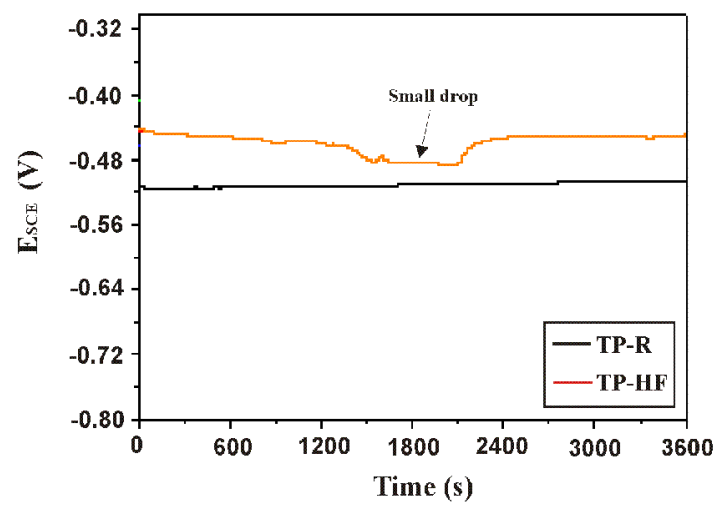

Figure 6. Open circuit potential curves for the filmed substrate (hybrid film) and for tinplate without coating.

shifted toward positive values compared with the uncoated tinplate (TR). This behavior is related to the presence of the barrier layer (hybrid film) between the substrate and the electrolyte, indicating an improved corrosion resistance ${ }^{32}$. Results reported in the literature show that the hybrid coatings present a higher anti-corrosion resistance than silane ones ${ }^{32}$.

However, this parameter experiences a small drop between around 1500 at 2200 second of the immersion in an aqueous $0.05 \mathrm{M} \mathrm{NaCl}$ solution, indicating that the Si$\mathrm{O}-\mathrm{Si}$ is not stable ${ }^{33,34}$. Consequently, the $\mathrm{Si}-\mathrm{O}-\mathrm{Si}$ reactions can suffer hydrolysis, forming again the $\mathrm{Si}-\mathrm{OH}$ hydrophilic groups so that electrolyte and ions can penetrate and react with the interface ${ }^{35}$.

\subsubsection{Electrochemical impedance spectroscopy}

Figure 7 and Figure 8 show, respectively, the Nyquist and Bode diagrams for samples with and without coating, 24 and 96 hours immersion in a $0.05 \mathrm{M} \mathrm{NaCl}$ solution.

The TP-HF sample showed the highest resistance values of impedance module (Figure 8) throughout the immersion 

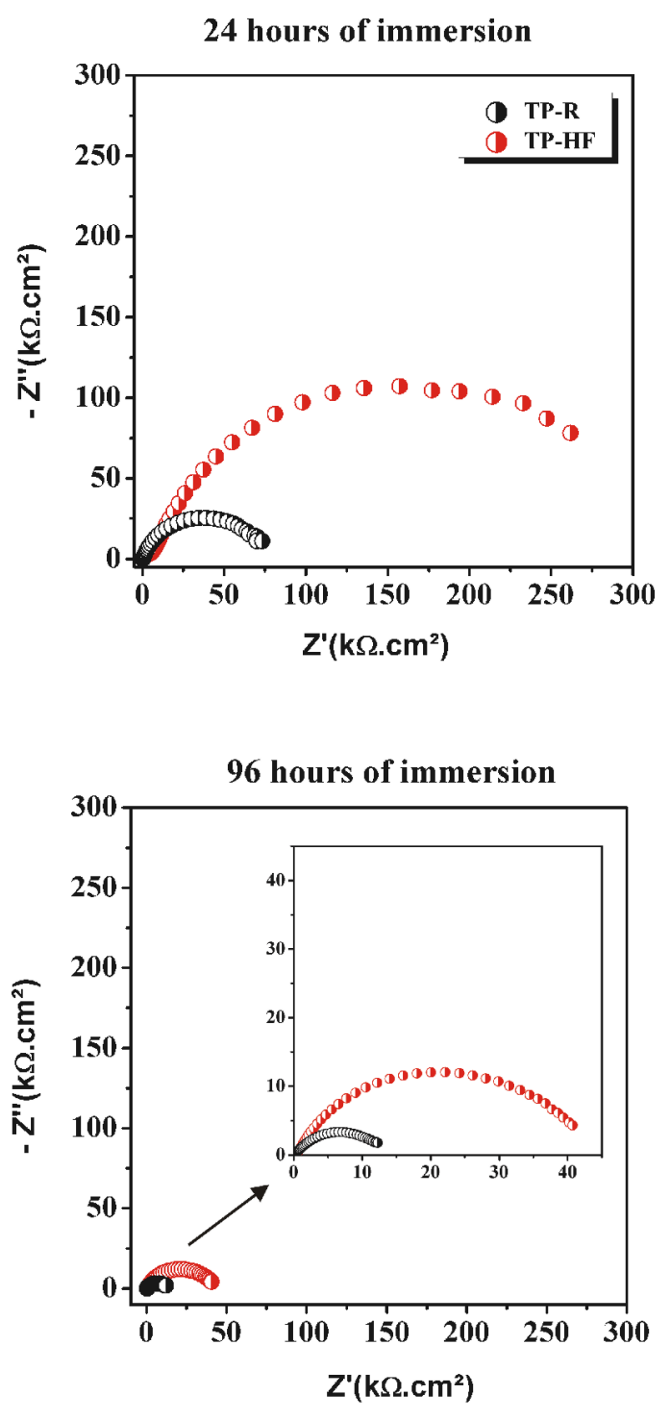

Figure 7. Nyquist diagrams for tinplate uncoated and tinplate coated with the hybrid films for 24 and 96 hours of immersion in $0.05 \mathrm{M} \mathrm{NaCl}$.

period as compared to the uncoated tinplate. This sample showed resistance values 3 times higher at 24 and 96 hours of immersion when compared to the uncoated substrate (TP-R) (Figure 8). This behavior demonstrates the protective action of hybrid films against corrosion and presented a more compact, even and probably denser layer. These results are consonance with other researcher ${ }^{35,36}$, in regards to the fact that the crack-free silane layer improves the barrier properties through its dense reticulation, which forms a less porous layer, thus enhancing the corrosion protection.

However, the resistance of the TP-HF system dropped 6 times from 24 to 96 hours of immersion. This behavior indicates that this system does not withstand long immersion times due to the fact that during the curing process, hydrophobic siloxane bonds are formed in the film network, which hinders water penetration. However, neither the precursor hydrolysis nor the cross-linking reactions (polycondensation) during curing are completed. Thus, non-hydrolyzed ester and hydrophilic $\mathrm{OH}$ groups are present in the films structures. These groups, ester and $\mathrm{OH}$, favor the uptake of water, while the siloxane can be hydrolyzed when the films are exposed to the electrolyte ${ }^{37}$.

The uncoated tinplate (TP-R) also shows a decrease in resistance of 5 times from 24 to 96 hours of immersion in an $0.05 \mathrm{M} \mathrm{NaCl}$ solution. At 24 hours of immersion, the protection is attributed to the tin oxides passivating top layer. However, this oxide does not withstand long immersion times and in 96 hours indicates an acceleration of the interfacial process associated with the tin oxides on the substrate surface ${ }^{38}$.

Figure 8 shows Bode diagrams obtained for 24 hours of immersion in the $\mathrm{NaCl}$ solution for the hybrid film (TP-HF) and for tin plate substrates. The time constant observed for tin plate in 24 hours was shifted to medium frequencies. This was attributed to the tin oxides passivating top layer ${ }^{39}$. The hybrid films showed a time constant in the high frequency range and a time constant in the medium to low frequency range (Figure 8). This phenomenon in the high frequency range is associated with the barrier properties of the hybrid film. On the other hand, the phenomenon observed at the medium to low frequency, indicates an acceleration of the interfacial process associated with the tin oxides on the substrate surface.

In 96 hours of immersion (Figure 8) the hybrid film presents one time constant at medium frequency, associated with the permeation of electrolyte through the hybrid film and reaching the tin oxides indicating an acceleration of the interfacial process associated with the tin oxides on the substrate surface. This could be explained by the non complete curing process and consequently not resistant to longs periods of immersion in the $0.05 \mathrm{M} \mathrm{NaCl}$ solution. In 96 hours of immersion the tinplate presented two overlapped time constants, indicating the degradation of the tin oxides. At the end of the experiment, red corrosion products were observed on the electrode surface, indicating that during the experiment, iron was dissolved and diffused to the surface, thus forming iron oxides.

Tables 4 and 5 show the values of the electric parameters obtained by the equivalent electric circuit fitted to the electrochemical impedance experimental data for the hybrid film (TP-HF) and the substrate (TP-R), respectively, up to $96 \mathrm{~h}$ of immersion by $0.05 \mathrm{M} \mathrm{NaCl}$ solution. Errors (\%) are shown in parentheses and were lower than $5 \%$ in most cases, which demonstrate the suitability of the circuit. These models use a combination of resistances, capacitances and other electrical components, which have a clear physical meaning related to the response of the electrochemical system ${ }^{37}$. In this work, we used only one electrical equivalent circuit model for the coated tinplate (TP-HF), which is shown in Figure 7.

In several circuits the capacitance was substituted by a CPE so as to take into account the non-ideality of the 

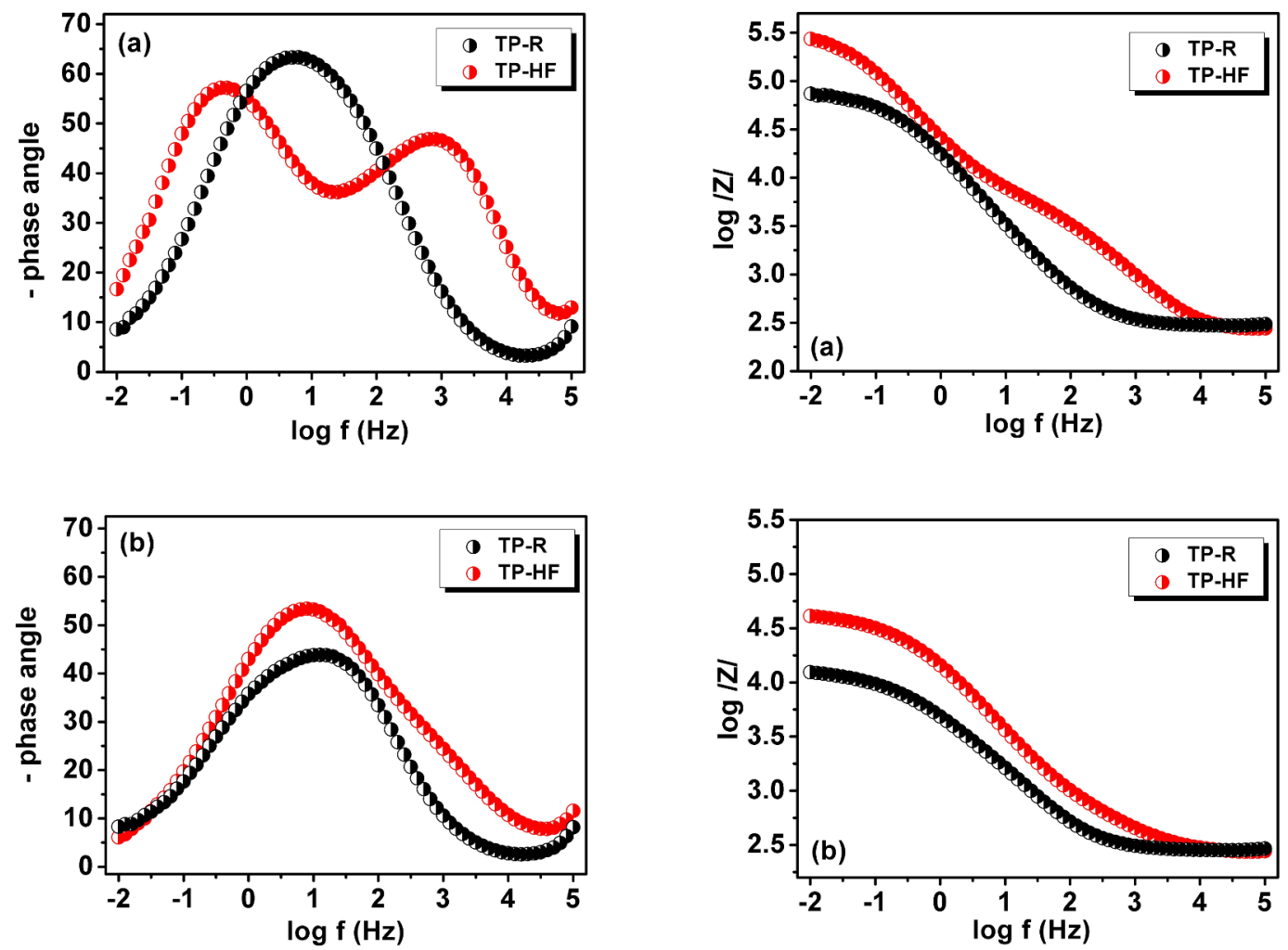

Figure 8. Bode diagrams for tinplate uncoated and tinplate coated with the hybrid films for (a) 24 and (b) 96 hours of immersion in 0.05 $\mathrm{M} \mathrm{NaCl}$.

Table 4. Equivalent circuits for the TP-HF sample. The error percentage is in parentheses.

\begin{tabular}{|c|c|c|c|c|c|}
\hline TP-HF & $1 \mathrm{~h}$ & $24 \mathrm{~h}$ & $48 \mathrm{~h}$ & $72 \mathrm{~h}$ & $96 \mathrm{~h}$ \\
\hline Circuit Simulation & 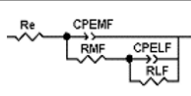 & 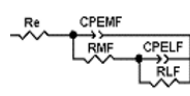 & $\stackrel{\text { Re }}{\sim \text { CPEMF }}$ & 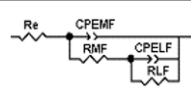 & $\sim_{\text {Re }}^{\text {CPEANF }} \stackrel{\text { CPANEF }}{\text { CPEEF }}$ \\
\hline $\operatorname{Re}\left(\Omega \cdot \mathrm{cm}^{2}\right)$ & $229(2.2)$ & $238(1.35)$ & $220(1.4)$ & $226(4.8)$ & $218(2.3)$ \\
\hline $\mathrm{CPE}_{\mathrm{MF}}\left(\mu \mathrm{F} \cdot \mathrm{cm}^{-2}\right)$ & $6.28(1.7)$ & $10(0.9)$ & $11.3(1.8)$ & $11.1(1.4)$ & $16.0(1.7)$ \\
\hline $\mathrm{n}$ & $0.74(0.9)$ & $0.75(0.75)$ & $0.73(4.7)$ & $0.74(0.9)$ & $0.69(1.1)$ \\
\hline $\mathrm{R}_{\mathrm{MF}}\left(\mathrm{k} \Omega \cdot \mathrm{cm}^{2}\right)$ & $1114(4.4)$ & 312 (1.9) & $115(1.4)$ & $58.0(5.1)$ & $44.8(2.1)$ \\
\hline $\mathrm{CPE}_{\mathrm{LF}}\left(\mu \mathrm{F} \cdot \mathrm{cm}^{-2}\right)$ & $10.62(8.5)$ & $31.03(5.5)$ & $90.31(8.5)$ & $128.5(7.1)$ & $136.8(3.7)$ \\
\hline $\mathrm{n}$ & $0.72(1.3)$ & $0.69(0.9)$ & $0.62(1.9)$ & $0.54(7.9)$ & $0.69(2.8)$ \\
\hline $\mathrm{R}_{\mathrm{LF}}\left(\mathrm{k} \Omega \cdot \mathrm{cm}^{2}\right)$ & $6.69(4.9)$ & $5.44(3.3)$ & $2.58(7.3)$ & $0.99(7.7)$ & $0.51(4.1)$ \\
\hline Chi-square $\left(10^{-3}\right)$ & 3.12 & 1.07 & 1.15 & 0.79 & 0.69 \\
\hline
\end{tabular}

tinplate and hybrid films. A value of $n=1$ corresponds to a smooth surface, and therefore the CPE should be substituted by an ideal capacitor $C$. A parameter of $n=0.5$ suggests a response of diffusion or porous material, and $0.5<\mathrm{n}<1$ was associated to heterogeneous, rough or non-homogeneous current distribution ${ }^{40,41}$. In the circuit, $\mathrm{Re}$ is the electrolyte resistance. The capacitors have been replaced by a constant phase element (CPE).

The corresponding circuit in Table 4 shows the best representation of the samples TP-HF for all immersion times studied. In these cases, we observed two time constants. A high to medium frequency constant $\left(\mathrm{R}_{\mathrm{MF}}\right.$ and $\left.\mathrm{CPE}_{\mathrm{MF}}\right)$ shows a phenomenon associated with the hybrid film barrier effect and also the presence of tin oxides on the metal surface. This behavior was also observed by other authors ${ }^{40,41}$, indicating that the hybrid films retard the process of corrosion of the metal substrate. The low frequency time constant $\left(\mathrm{R}_{\mathrm{BF}}\right.$ and $\mathrm{CPE}_{\mathrm{BF}}$ ) may be associated with the corrosion of the electrode produced by permeation through the film, which happens due to the permeation of the electrolyte through gaps in the 
Table 5. Equivalent circuits for the TP-R sample. The error percentage is in parentheses.

\begin{tabular}{|c|c|c|c|c|c|}
\hline TP-R & $1 \mathrm{~h}$ & $24 \mathrm{~h}$ & $48 \mathrm{~h}$ & $72 \mathrm{~h}$ & $96 \mathrm{~h}$ \\
\hline Circuit Simulation & 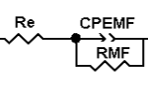 & $\overbrace{\text { Re }}^{\mathrm{Re}} \overbrace{\text { CPMF }}^{\mathrm{CPEMF}}$ & 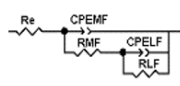 & 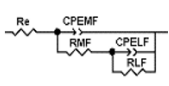 & 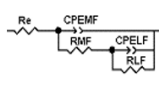 \\
\hline $\operatorname{Re}\left(\Omega \cdot \mathrm{cm}^{2}\right)$ & $168.4(0.9)$ & $1586(0.7)$ & $159.4(0.3)$ & $158.7(0.4)$ & $157.9(0.6)$ \\
\hline CPEMF $\left(\mu \mathrm{F} . \mathrm{cm}^{-2}\right)$ & $15.0(0.9)$ & $1.86(1.3)$ & $21.7(1.3)$ & $26.9(4.4)$ & $28.6(7.2)$ \\
\hline $\mathrm{n}$ & $0.84(0.3)$ & $0.83(0.3)$ & $0.81(0.3)$ & $0.78(0.8)$ & $0.78(1.6)$ \\
\hline $\operatorname{RMF}\left(\mathrm{k} \Omega \cdot \mathrm{cm}^{2}\right)$ & $214(1.9)$ & $285(1.5)$ & $12.5(6.8)$ & $1.22(7.3)$ & $0.39(6.7)$ \\
\hline CPELF $\left(\mu \mathrm{F} . \mathrm{cm}^{-2}\right)$ & - & - & $238(6.9)$ & $166(1.8)$ & $302(0.6)$ \\
\hline $\mathrm{n}$ & - & - & $0.38(5.2)$ & $0.43(1.8)$ & $0.49(0.9)$ \\
\hline $\operatorname{RLF}\left(\mathrm{k} \Omega . \mathrm{cm}^{2}\right)$ & - & - & $10.4(4.7)$ & $11.6(2.5)$ & $7.28(1.6)$ \\
\hline Chi-square (10-3) & 3.56 & 3.15 & 0.28 & 0.15 & 0.22 \\
\hline
\end{tabular}

hybrid film. With an increase in the immersion time, there is an increase of the pore size. This indicates the transition period between the electrode behavior of flat and porous films, which allows the co-existence of flat and porous films ${ }^{42}$.

For the uncoated tinplate (Table 5), only one time constant is observed for 1 and 24 hours of immersion, and this time constant was attributed to the tin oxides. After 48 hours of immersion, tinplate exhibited two overlapping time constants. A similar result as has been observed by other authors $^{6}$, which indicates the degradation of the tin oxides and probably the metal corrosion, as a new process governed by diffusion apparently begins as indicated by the low value of $\mathrm{n}$. This explanation is corroborated by the fact that there is, initially, a high and medium resistance, which declines drastically and that red corrosion products were observed on the electrode surface at the end of the experiment, indicating the formation of iron oxides (Figure 8-a).

Figure 9 shows a representation of the interface between the sample/electrolyte, equivalent to an electric circuit simulation of the data obtained after 96 hours of EIS. The corrosion process involves several simultaneous physical processes and thus, the corresponding equivalent circuit can be composed of various circuit elements. After 96 hours of EIS the equivalent circuit associated with the behavior of both samples (TP-R and TP-HF) is identical. In the TP-R sample the medium frequency constant $\left(\mathrm{R}_{\mathrm{MF}}\right.$ and $\left.\mathrm{CPE}_{\mathrm{MF}}\right)$ is related to the presence of tin oxide on the metal surface. As to the TP-HF sample, the medium frequency constant $\left(\mathrm{R}_{\mathrm{MF}}\right.$ and $\left.\mathrm{CPE}_{\mathrm{MF}}\right)$ is related to the association of the hybrid film and the tin oxide.

Tables 4 and 5 show that the $\mathrm{R}_{\mathrm{MF}}$ after 96 hours of immersion for the TP-HF sample is $44.8 \mathrm{k} \Omega . \mathrm{cm}^{2}$, while for the TP-R sample is $0.39 \mathrm{k} \Omega . \mathrm{cm}^{2}$. This result indicates that the hybrid film associated with the tin oxide (TP-HF sample) has an effective protective action (barrier effect) even after 96 hours of immersion, being far superior to the protection exerted by tin oxide alone (TP-R sample). The painting may undergo performance issues depending on the specific situation to which it was submitted. Therefore, the hybrid film acts as an effective temporary barrier, preventing the action of corrosive species on the substrate. Thus, temporary minimal protection is guaranteed to the system until the fault in the organic coating is resolved, ensuring product integrity.

Figure 10 shows the images of the hybrid films (TP$\mathrm{HF}$ ) and uncoated tinplate (TP-R) studied after 96 hours of immersion in the electrochemical impedance test. The TP-R samples showed more corrosion products in relation to the hybrid film. This was expected and confirms the results obtained in electrochemical tests.
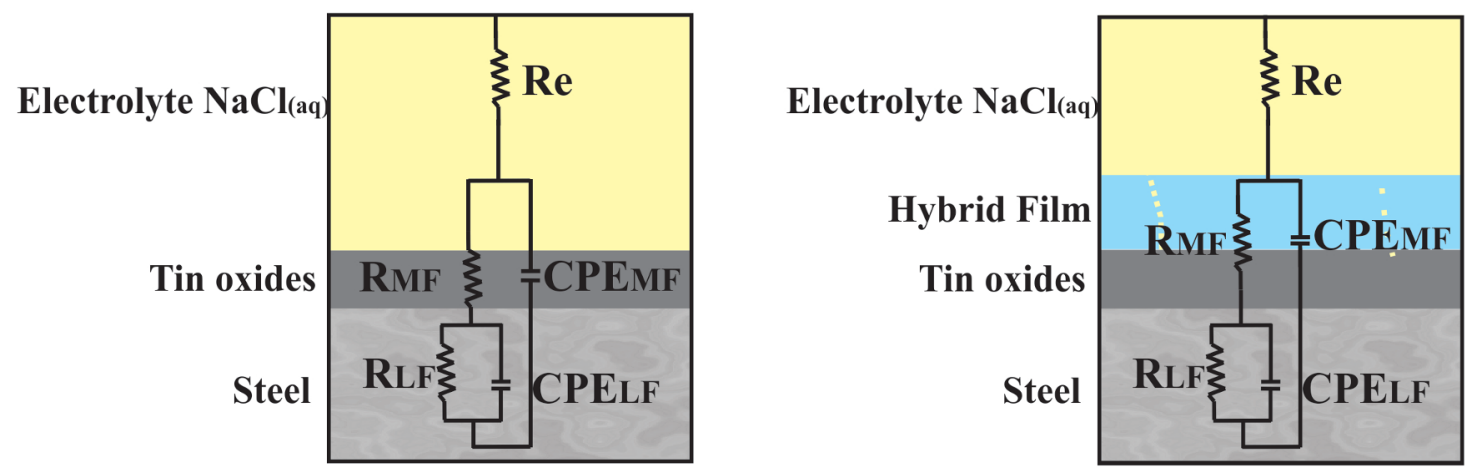

Figure 9. Physical model of the studied samples, presenting the general equivalent circuit after 96 hours of EIS 


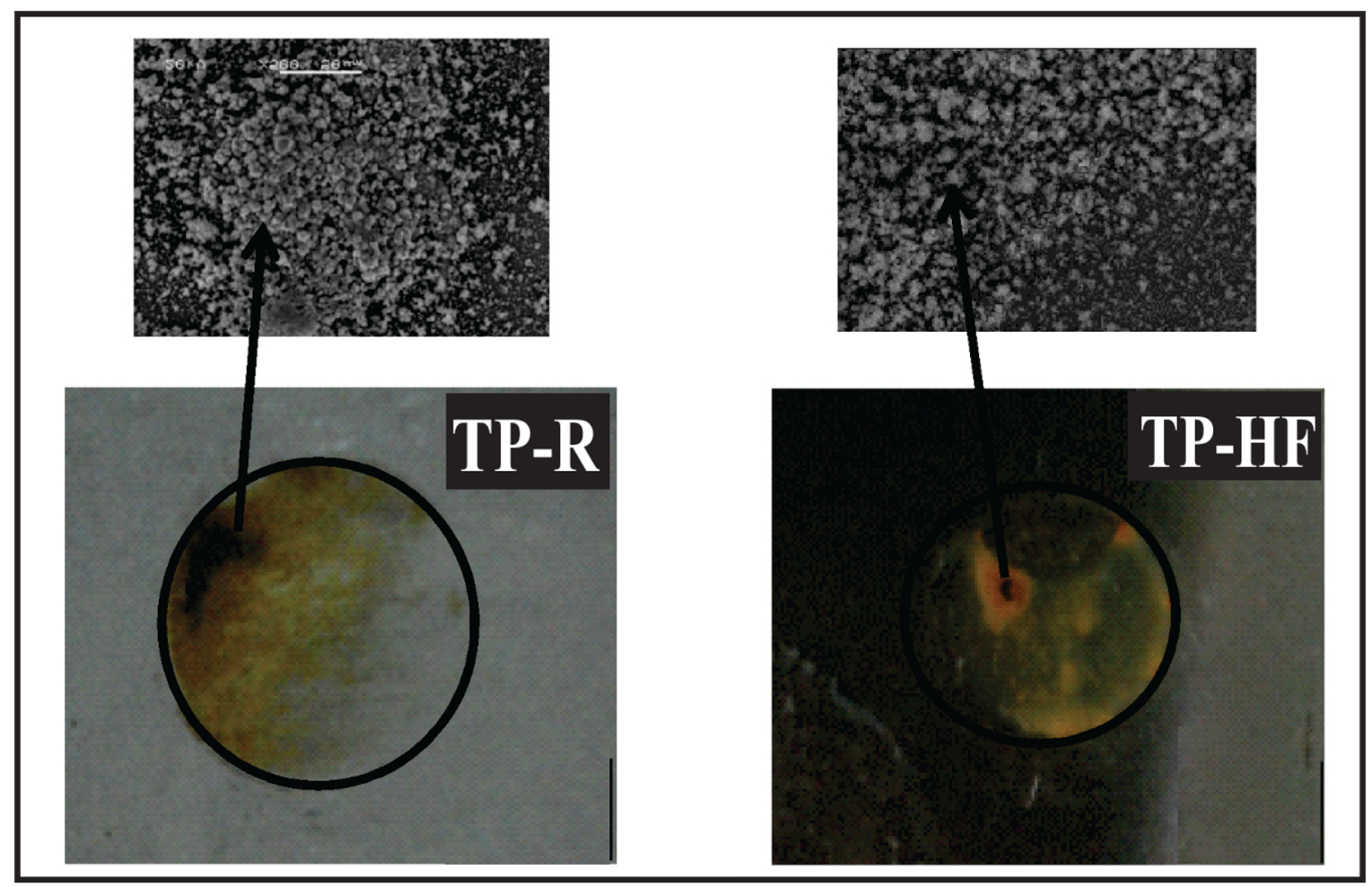

Figure 10. Images obtained after 96 hours of EIS of the samples.

TP-HF sample also had a good electrochemical performance due to its compact structure, as seen in SEM micrographs in Figure 4. In this system, the permeation of the electrolyte was prevented by the presence of this film on the substrate, which is in accordance with the results obtained from the open circuit potential (Figure 6).

\subsubsection{Immersion test}

\subsubsection{Tinplate corrosion}

Figure 11 shows the tinplate after 48 hours of immersion in $0.05 \mathrm{M} \mathrm{NaCl}$. In Figure 11-a, preferential points can be easily observed which created corrosion and corrosion products around them. The diluted electrolyte caused very significant attacks on tinplate. However, the tin layer is about $1 \mu \mathrm{m}$, and if it was uniform and without defects should protect iron longer, but it is observed red corrosion of the iron, for possibly tin layer has discontinuities and defects. The immersion assay (Figure 11) shows that part of the tin coating was corroded and the carbon steel was exposed to the electrolyte and so began to corrode ${ }^{1,2,9}$, releasing iron ions (Equation 1). The dissolved oxygen (Equation 2) react with iron ions, yielding the ferrous hydroxide (Equation 3), which is then oxidized and converted to ferric hydroxide $\left(\mathrm{Fe}_{3} \mathrm{O}_{2} \cdot \mathrm{H}_{2} \mathrm{O}\right)$ of reddish color (Equations 4 and 5).

$$
\begin{gathered}
\mathrm{Fe} \rightarrow \mathrm{Fe}^{2+}+2^{e^{-}} \\
1 / 2 \mathrm{O}_{2}+\mathrm{H}_{2} \mathrm{O}+2^{e^{-}} \rightarrow 2(\mathrm{OH})^{-} \\
\mathrm{Fe}^{2+}+2 \mathrm{OH}^{-} \rightarrow \mathrm{Fe}(\mathrm{OH})_{2} \\
\mathrm{Fe}(\mathrm{OH})_{2}+(\mathrm{OH})^{-} \rightarrow \mathrm{Fe}(\mathrm{OH})_{3} \\
2 \mathrm{Fe}(\mathrm{OH})_{3} \rightarrow \mathrm{Fe}_{2} \mathrm{O}_{3} \mathrm{H}_{2} \mathrm{O}+2 \mathrm{H}_{2} \mathrm{O}
\end{gathered}
$$

Figure 11-b shows tinplate roughness and corrosion embossing/roughness of the sample. Therefore, deposits of corrosion can be observed in individual regions that will corrode, which is related to the roughness of the sample. The most rugged regions will corrode preferentially.

By increasing the exposition time, the electrolyte permeated the tinplate substrate through cracks and/or imperfections in the tin and starting the corrosion because of the exposed metal. In the electrolyte $\mathrm{NaCl}$ solution (Equation 6), the movement of ions increased the electrical conductivity of the solution and the chloride ions propitiate the beginning of the metal corrosion process.

$$
\mathrm{NaCl}+\mathrm{H}_{2} \mathrm{O} \rightarrow \mathrm{Na}^{+}+\mathrm{Cl}^{-}+\mathrm{H}_{2} \mathrm{O}
$$




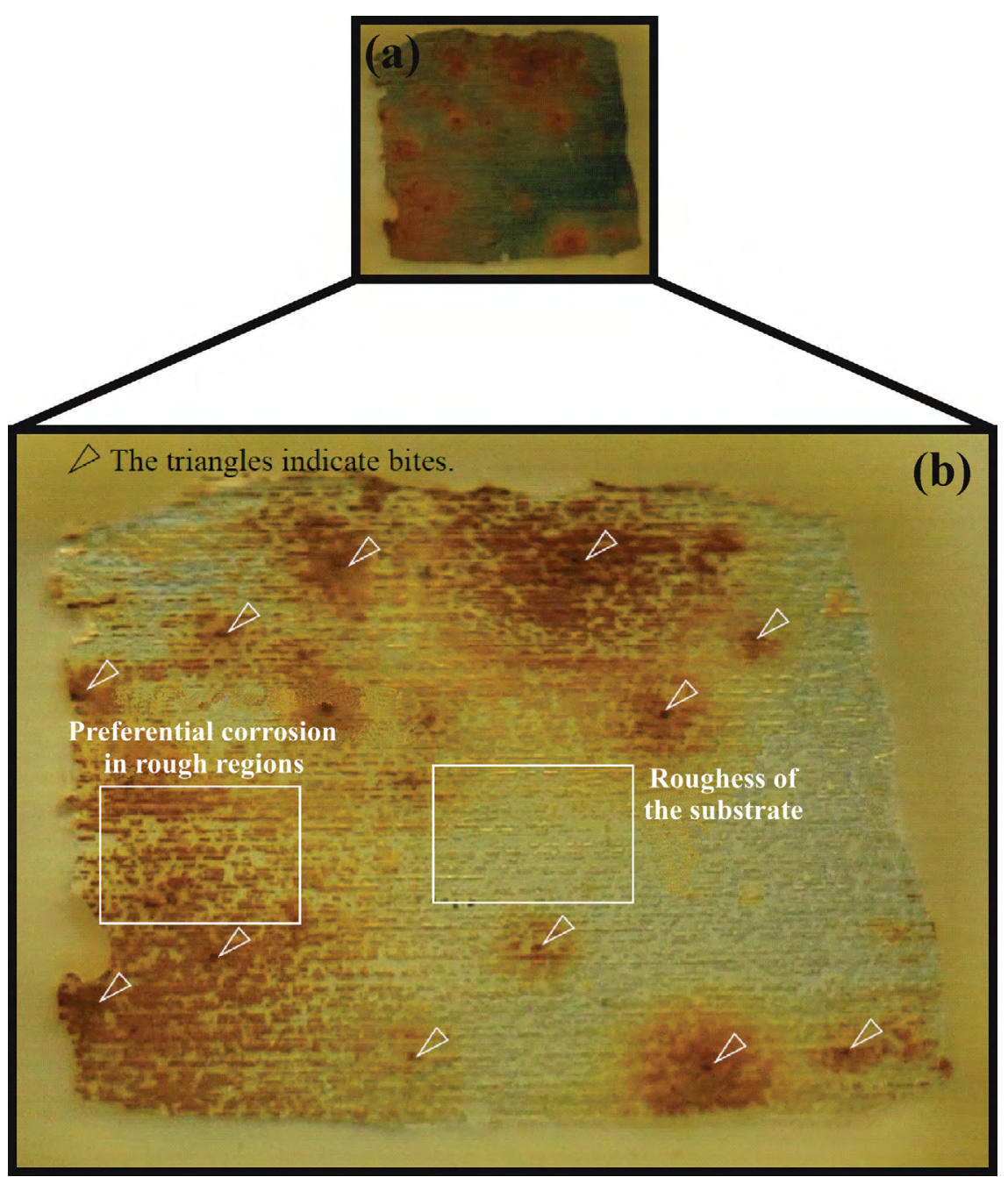

Figure 11. Tinplate after 48 hours immersion in $0.05 \mathrm{M} \mathrm{NaCl}$.

Subsequently, the protective performance of the tin layer was deteriorated and the ions $\mathrm{Sn}^{2+}$ (Equation 7) flowed from the tin.

$$
S n \rightarrow S n^{2+}+2 e^{-}
$$

\subsubsection{Corrosion of tinplate coated with hybrid film}

Further analysis of the immersion test was proposed to verify the mechanism of corrosion of the tinplate coated with hybrid film (TP-HF). The sample with hybrid film (PD-HF) underwent the same form of corrosive attack observed on the uncoated sample (TP-R), yet the process is slower. This difference was observed in the electrochemical impedance tests.

Figure 12 shows a selection of micrographs that illustrates the behavior of the TP-HF sample after 6 days of immersion in $0.05 \mathrm{M} \mathrm{NaCl}$ solution. As Figure 11-a depicts, there is the formation of corrosion products isolated on the surface of the sample. This indicates that the corrosion product was generated at points and/or individual regions that will corrode preferentially, related to the roughness of the tinplate substrate.

Figure 12-b shows that corrosion products accumulate under the hybrid film, i.e., corrosion starts due to failure or discontinuities in the coating and begins to corrode, then it spreads and accumulates underneath the hybrid film until reaching a moment when the quantity of corrosion products is great enough to break the sol-gel coating. The products begin to appear on the top of the coating (Figure 12-c) where there is sol-gel broken up by the corrosion products.

The most rugged regions will corrode preferentially, and these defects were observed in the uncoated tinplate (Figure 11-b). This form of corrosion also happens with the application of the hybrid film. The red color arises because of corrosion from the tinplate sheet metal, and as previously seen, there are many defects and irregularities in the tin layer, as can be seen in the increased images after the products of corrosion were washed, as shown in Figure 12-d. 


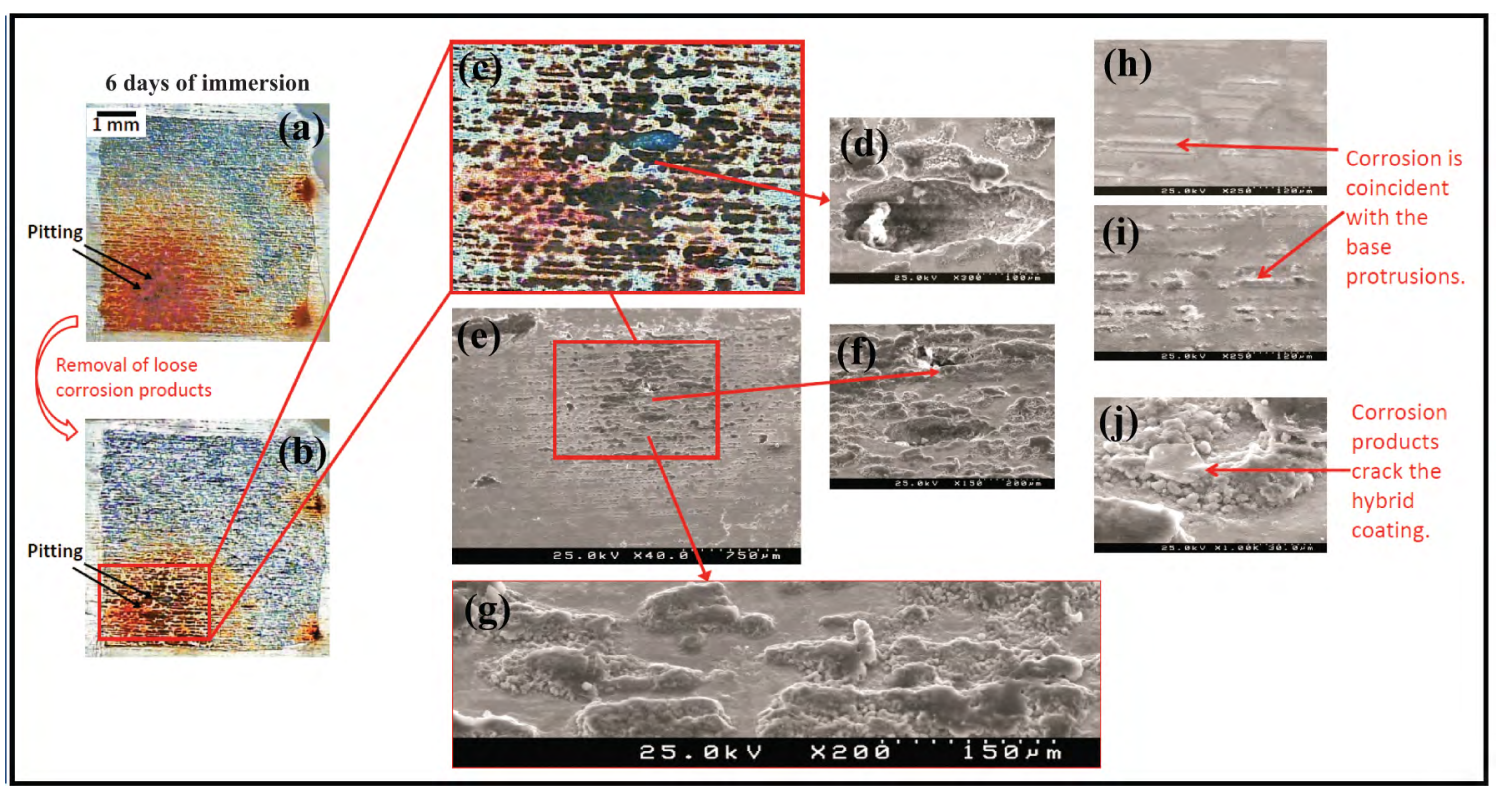

Figure 12. Selection of images obtained from the TP-HF sample after 6 days immersion in $0.05 \mathrm{M} \mathrm{NaCl}$.

(a) As expected the system to be: films without defects, with constant thickness and perfect adhesion on the entire surface.

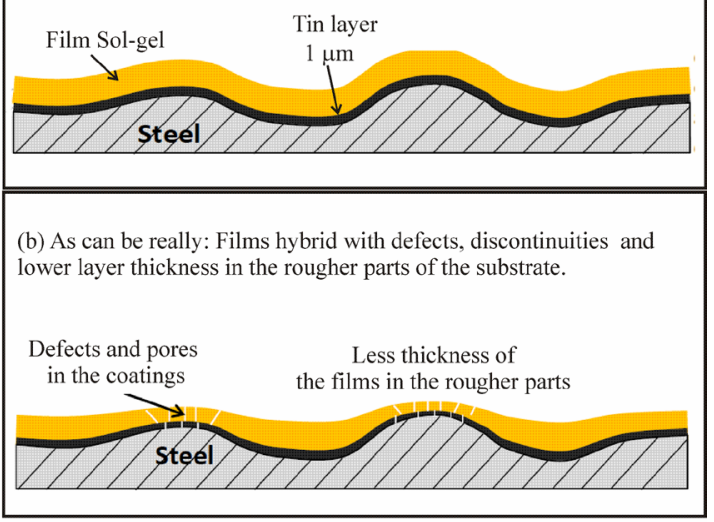

(c) Preferential corrosion in less resilient regions: corrosion in the protruding zones roughness. First corrosion occurs beneath the hybrid film. Next, the corrosion products break the film and are visible directly.

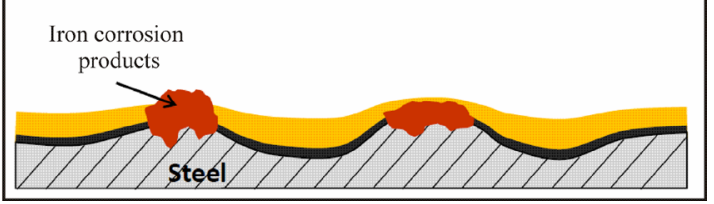

Figure 13. Corrosion mechanism for the tinplate coated with hybrid film in the electrolyte $\mathrm{NaCl}$ solution.

Figure 12-e shows, in more detail, the corrosion formed on the surface of the TP-HF sample. A detailed analysis of the SEM image of the sample shows that corrosion occurs at specific points (Figures 12-f-g). Moreover, it is noted that the corrosion products appear mainly in the hybrid film irregularities, which are shaped irregularities and/ or the roughness of the tinplate. Those areas in which the corrosion starts preferentially, are defects of the film and the tin layer reaching the iron, producing a reddish color in the corrosion product.

Figure 12-h indicates that corrosion occurs by irregularities, where there is a degradation of the hybrid film forming clusters and under these clusters there are corrosion products resulting from the defects in the substrate. Furthermore, the microscopic image showed abundant dark corrosion products indicating the degradation of the tin oxides.

Figure 13 shows the corrosion mechanism for tinplate coated with hybrid film in the $\mathrm{NaCl}$ electrolyte solution. In this scheme, the spot corrosion was omitted, that is, pitting occurred. In this case, another form of corrosion will be highlighted.

\subsection{Scanning vibrating electrode test}

Figure 14 shows the images of the surface and SVET maps of the uncoated tinplate (TP-R). The green color corresponds to zero current, the blue color corresponds to negative currents (cathode) and red color is related to the positive current (anode).

The tinplate corrosion (TP-R) was detected from the beginning of the immersion, with localized anodic and cathodic spots being the remaining area. In 24 hours of immersion 8 pits were observed in an area of $16 \mathrm{~mm}^{2}$. After 120 hours, some original pits were gone and the corrosion migrated to other regions of the sample. The anodic activity was significantly located in a region with abundant accumulation of corrosion products. The rest of the surface presented cathodic activity around $-2 \mu \mathrm{A} \mathrm{cm} \mathrm{cm}^{-2}$. Interestingly, a slight increase of cathodic activity was measured above the inactive 


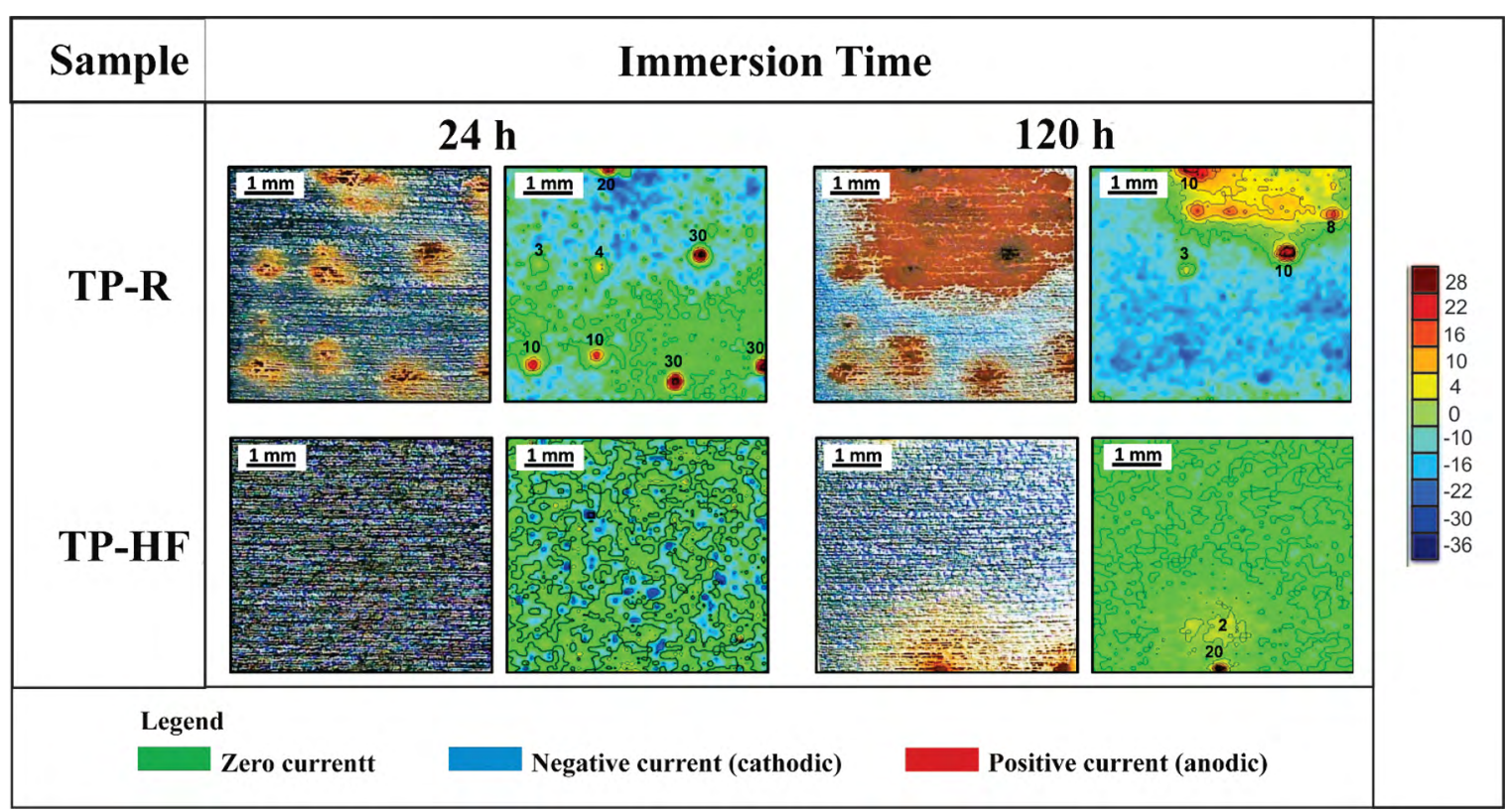

Figure 14. SVET micrographs of the samples, after $24 \mathrm{~h}$ and $120 \mathrm{~h}$ of immersion in $0.05 \mathrm{M} \mathrm{NaCl}$.

pits. This may be due to the deposition of corrosion products from iron, which can increase the cathodic activity through an increased surface area site or improving the catalytic oxygen reduction reaction.

The hybrid film sample (TP-HF) showed an efficient protective effect, as corrosion was detected only on the second day of immersion with a small pit. After 120 hours of immersion, this sample showed only two small points of corrosion, and only one of them was active.

\section{Conclusions}

The results showed a galvanic coupling between the $\mathrm{Sn} / \mathrm{SnO}_{2}$ coat (cathode) and the ferrous base exposed at the defects (anode). The organic-inorganic hybrid film was able to retard the corrosion of the tinplate.

Furthermore, the corrosion products of the hybrid films showed that the corrosion occurs at the irregularities arising from defects in the substrate. First, corrosion occurs in the areas of protruding roughness under the first hybrid film but then corrosion products break the film and are visible directly. Similarly to the tinplate without coating, but at a higher speed in the beginning, there are corrosion deposits that are, in fact, isolated regions that will corrode, related to the roughness of the sample. Thus, the most rugged regions will corrode preferentially.

The results obtained by the SVET showed that the TP-HF sample had a good performance when immersed in the $\mathrm{NaCl}$ solution. The corrosion was detected only at the second day of immersion with a small pit. After 120 hours this system displayed just two small points of corrosion, indicating the effective barrier effect of the film.
Based on the results, we found that the hybrid film that was developed on a TMSM and TEOS base is effective as a protective coating when applied on tinplate. The presence of the hybrid film retards the action of corrosion and ensures the integrity of the tinplate for longer when exposed to aggressive media.

\section{Acknowledgments}

The authors would like to express their gratitude for the financial support of CAPES (a Brazilian Governmental agency for the development of human resources) and $\mathrm{CNPq}$ (the Brazilian National Council for Scientific and Technological Development).

\section{References}

1. Xia D, Wang J, Song S, Zhong B, Han Z. The Corrosion Behavior of Lacquered Tinplate in Functional Beverage. Advanced Materials Research. 2011;233-235:1747-1751.

2. Zumelzu E, Cabezas C. Observations on the influence of microstructure on electrolytic tinplate corrosion. Materials Characterization. 1995;34(2):143-148.

3. Chen S, Xie L, Xue F. X-ray photoelectron spectroscopy investigation of commercial passivated tinplate surface layer. Applied Surface Science. 2013;276:454-457.

4. Álvarez D, Collazo A, Pérez C. The use of sol-gel film as pretreatment for tinplate used in the canning industry. Progress in Organic Coatings. 2013;76(12):1819-1826.

5. Álvarez D, Collazo A, Nóvoa XR, Pérez C. The anticorrosive properties of sol-gel films doped with hydrotalcite nanoparticles applied on tinplate. Electrochimica Acta. 2014;131:137-147. 
6. Álvarez D, Collazo A, Nóvoa XR, Pérez C. Electrochemical behavior of organic/inorganic films applied on tinplate in different aggressive media. Progress in Organic Coatings. 2014;77(12 Pt A):2066-2075.

7. Xia D, Song S, Wang J, Bi H, Jiang Y, Han Z. Corrosion behavior of tinplate in $\mathrm{NaCl}$ solution. Transactions of Nonferrous Metals Society of China. 2012;22(3):717-724.

8. Martins JI. Corrosion problems in tinplate cans for storing contact glues for shoes. Engineering Failure Analysis. 2012;26:258265.

9. Carbonini P, Monetta T, Nicodemo L, Mastronardi P, Scatteia B, Belluci F. Electrochemical characterization of multilayer organic coatings. Progress in Organic Coatings. 1996;29(14):13-20.

10. Murillo-Gutiérrez NV, Ansart F, Bonino JP, Kunst SR, Malfatti CF. Architectural optimization of an epoxy-based hybrid solgel coating for the corrosion protection of a cast Elektron 21 magnesium alloy. Applied Surface Science. 2014;309:62-73.

11. Rosalbino F, Scavino G, Mortarino G, Angelini E, Lunazzi G. EIS study on the corrosion performance of a $\mathrm{Cr}$ (III)-based conversion coating on zinc galvanized steel for the automotive industry. Journal of Solid State Electrochemistry. 2010;15(4):703709.

12. Huang X, Li N, Wang H, Sun H, Sun S, Zheng J. Electrodeposited cerium film as chromate replacement for tinplate. Thin Solid Films. 2008;516(6):1037-1043.

13. Brusciotti F, Batan A, De Graeve I, Wenkin M, Biessemans $\mathrm{M}$, Willem R, et al. Characterization of thin water-based silane pre-treatments on aluminium with the incorporation of nanodispersed $\mathrm{CeO}_{2}$ particles. Surface and Coatings Technology. 2010;205(2):603-613.

14. Shi H, Liu F, Han E. Corrosion behaviour of sol-gel coatings doped with cerium salts on 2024-T3 aluminum alloy. Materials Chemistry and Physics. 2010;124(1):291-297.

15. Nincević Grassino A, Grabarić Z, Pezzani A, Fasanaro G, Lo Voi A. Influence of essential onion oil on tin and chromium dissolution from tinplate. Food and Chemical Toxicology. 2009;47(7):1556-1561.

16. Hu H, Li N, Cheng J, Chen L. Corrosion behavior of chromiumfree dacromet coating in seawater. Journal of Alloys and Compounds. 2009;472(1-2):219-224.

17. Palomino LM, Suegama PH, Aoki IV, Montemor MF, de Melo HG. Electrochemical study of modified non-functional bis-silane layers on Al alloy 2024-T3. Corrosion Science. 2008;50(5):1258-1266.

18. Naderi R, Fedel M, Deflorian F, Poelman M, Olivier M. Synergistic effect of clay nanoparticles and cerium component on the corrosion behavior of eco-friendly silane sol-gel layer applied on pure aluminum. Surface and Coatings Technology. 2013;224:93-100.

19. Kunst SR, Beltrami LVR, Cardoso HRP, Vega MRO, Baldin EKK, Menezes TL, et al. Effect of curing temperature and architectural (monolayer and bilayer) of hybrid films modified with polyethylene glycol for the corrosion protection on tinplate. Materials Research. 2014;17(4):1071-1081.
20. Deflorian F, Rossi S, Fedrizzi L, Fedel M. Integrated electrochemical approach for the investigation of silane pretreatments for painting copper. Progress in Organic Coatings. 2008;63(3):338-344.

21. Isaacs HS. The measurement of the galvanic corrosion of soldered copper using the scanning vibrating electrode technique. Corrosion Science. 1988;28(6):547-558.

22. Aldykiewicz AJ Jr., Isaacs HS. Dissolution characteristics of duplex stainless steels in acidic environments. Corrosion Science. 1998;40(10):1627-1646.

23. Ogle K, Baudu L, Garrigues T, Philippe X. Localized Electrochemical Methods Applied to Cut Edge Corrosion. Journal of the Electrochemical Society. 2000;147(10):3654-3660.

24. Vuillemin B, Philippe X, Oltra R, Vignal V, Coudreuse L, Dufour LC, et al. SVET, AFM and AES study of pitting corrosion initiated on $\mathrm{MnS}$ inclusions by microinjection. Corrosion Science. 2003;45(6):1143-1159.

25. Bastos AC, Karavai OV, Zheludkevich ML, Yasakau KA, Ferreira MGS. Localised Measurements of $\mathrm{pH}$ and Dissolved Oxygen as Complements to SVET in the Investigation of Corrosion at Defects in Coated Aluminum Alloy. Electroanalysis. 2010;22(17-18):2009-2016.

26. Malfatti CF, Menezes TL, Radtke C, Esteban J, Ansart F, Bonino JP. The influence of cerium ion concentrations on the characteristics of hybrid films obtained on AA2024-T3 aluminum alloy. Materials and Corrosion. 2012;63(9):819-827.

27. Kunst SR, Cardoso HRP, Ortega MR, Beltrami LVR, Menezes TL, Malfatti CF. The effects of curing temperature on bilayer and monolayer hybrid films: mechanical and electrochemical properties. Journal of Applied Electrochemistry. 2014;44(7):759771.

28. Kunst SR, Beltrami LVR, Cardoso HRP, Menezes TL, Malfatti CF. UV Curing Paint on Hybrid Films Modified with Plasticizer Diisodecyl Adipate Applied on Tinplate: The Effects of Curing Temperature and the Double Layer. Industrial and Engineering Chemistry Research. 2014;53(49):19216-19227.

29. Marcolin P, Beltrami LVR, Souza JM, Boniatti R, Menezes TL, Correa CA, Quevedo MC, Bastos AC, Ferreira MGS, Oliveira CT, Moura ABD, Fuhr LT, Schneider EL, Malfatti CF, Kunst SR. Influence of the Polyethyleneglycol Plasticizer on the on the Mechanical and Electrochemical Properties of Siloxane Hybrid Films Applied on Tinplate. International Journal of Electrochemical Science. 2017; 12:943-958.

30. Wang M, He D, Xie H, Fu L, Yu Y, Zhang Q. Characterization of bis-[triethoxysilylpropyl] tetrasulfide layers on aluminum based on water-based silanization solution. Thin Solid Films. 2012;520(17):5610-5615.

31. Sakai RT, CruzFMDL, Melo HG, BenedettiAV, Santilli CV, Suegama PH. Electrochemical study of TEOS, TEOS/MPTS, MPTS/MMA and TEOS/MPTS/MMA films on tin coated steel in $3.5 \% \mathrm{NaCl}$ solution. Progress in Organic Coatings. 2012;74(2):288-301.

32. Sarmento VHV, Schiavetto MG, Hammer P, Benedetti AV, Fugivara CS, Suegama PH, et al. Corrosion protection of stainless steel by polysiloxane hybrid coatings prepared using the sol-gel process. Surface and Coatings Technology. 2010;204(16-17):2689-2701. 
33. Behzadnasab M, Mirabedini SM, Kabiri K, Jamali S. Corrosion performance of epoxy coatings containing silane treated $\mathrm{ZrO}_{2}$ nanoparticles on mild steel in $3.5 \% \mathrm{NaCl}$ solution. Corrosion Science. 2011;53(1):89-98.

34. van Ooij WJ, Zhu D, Stacy M, Seth A, Mugada T, Gandhi J, et al. Corrosion Protection Properties of Organofunctional Silanes-An Overview. Tsinghua Science \& Technology. 2005;10(6):639664.

35. van Ooij WJ, Zhu D. Electrochemical Impedance Spectroscopy of Bis-[Triethoxysilypropyl]Tetrasulfide on A1 2024-T3 Substrates. Corrosion. 2001;57(5):413-427.

36. Zhu D. Corrosion Protection of Metals by Silane Surface Treatment. [Thesis]. Cincinnati: University of Cincinnati; 2005.

37. Suegama PH, Sarmento VHV, Montemor MF, Benedetti AV, Melo HG, Aoki IV, et al. Effect of cerium (IV) ions on the anticorrosion properties of siloxane-poly(methyl methacrylate) based film applied on tin coated steel. Electrochimica Acta. 2010;55(18):5100-5109.
38. Souza MEP, Ariza E, Ballester M, Yoshida IVP, Rocha LA, Freire CMA. Characterization of organic-inorganic hybrid coatings for corrosion protection of galvanized steel and electroplated ZnFe steel. Materials Research. 2006;9(1):59-64.

39. Jayaraj B, Desai VH, Lee CK, Sohn YH. Electrochemical impedance spectroscopy of porous $\mathrm{ZrO}_{2}-8$ wt. $\% \mathrm{Y}_{2} \mathrm{O}_{3}$ and thermally grown oxide on nickel aluminide. Materials Science and Engineering: A. 2004;372(1-2):278-286.

40. Conde A, Damborenea JJ. Electrochemical impedance spectroscopy for studying the degradation of enamel coatings. Corrosion Science. 2002;44(7):1555-1567.

41. Bajat JB, Milošev I, Jovanović Ž, Jančić-Heinemann RM, Dimitrijević M, Mišković-Stanković VB. Corrosion protection of aluminium pretreated by vinyltriethoxysilane in sodium chloride solution. Corrosion Science. 2010;52(3):1060-1069.

42. Varma PCR, Colreavy J, Cassidy J, Oubaha M, McDonagh C, Duffy B. Corrosion protection of AA 2024-T3 aluminium alloys using 3, 4-diaminobenzoic acid chelated zirconium-silane hybrid sol-gels. Thin Solid Films. 2010;518(20):5753-5761. 